\title{
建筑工程框架结构施工技术探索
}

\author{
李乃瑛 \\ 丰县孙楼街道办事处，江苏 徐州 221700
}

[摘要] 建筑工程行业的发展, 对于我国社会建设发展与经济发展的影响作用较为明显, 近些年建筑工程在结构设计方面进行 了很多优化创新, 结构形式种类多样。而框架结构是现代建筑工程应用最为广泛的结构形式, 其施工质量与安全是人们最关 注的问题。文就针对建筑工程框架结构的施工进行研究, 对框架结构施工的重点以及施工技术应用进行探索分析。 [关键词]建筑工程; 框架结构; 施工技术

DOI：10.33142/aem.v2i12.3408 中图分类号: TU9 文献标识码：A

\section{Exploration on Construction Technology of Frame Structure in Construction Engineering}

LI Naiying

Fengxian Sunlou Jiedao Banshichu, Xuzhou, Jiangsu, 221700, China

\begin{abstract}
The development of the construction industry has a significant impact on the development of social construction and economic development in China. In recent years, many optimization and innovation have been carried out in the structural design of construction engineering, with a variety of structural forms. The frame structure is the most widely used structural form in modern construction engineering and its construction quality and safety are the most concerned problems. This paper studies the construction of frame structure in construction engineering and explores and analyzes the key points of frame structure construction and the application of construction technology.
\end{abstract}

Keywords: construction engineering; frame structure; construction technology

\section{引言}

近些年我国建筑工程施工活动在各地区开展的都较为频繁, 建筑工程用地资源紧缺的现象逐渐显露, 因而建筑工 程框架结构层数越来越多, 对于框架结构施工的质量与安全提出了更高的要求。框架结构施工当中, 施工技术的应用 对于结构性能、质量有着直接的影响, 保证施工技术规范和应用适宜性, 是工程框架结构质量、性能强化的关键。

\section{1 建筑工程框架施工的重点分析}

\section{1 钢筋框架工程施工重点}

建筑工程框架当中钢筋是重要组成结构, 钢筋框架工程施工对于整体结构的质量有直接影响作用力。钢筋结构之 间的建设跨度相对较长, 并且是与混凝土结构交叉组成一个完整的框架结构, 钢筋结构的防护与坚固性强化是施工质 量提升的重点。在钢筋工程施工当中, 首要任务就是保证钢筋材料的质量达到工程建设标准, 钢筋规格符合工程设计 要求。钢筋结构施工完成之后, 会将混凝土材料进行灌注加固衔接, 在这一施工过程中很容易出现钢筋结构位移或变 形的情况, 因而对这一问题的控制也是施工重点。还有钢筋结构定位误差控制与钢筋结构承载力强化、钢筋衔接结构 性能强化等也都是施工中需要关注的环节。

\section{2 混凝土框架工程施工重点}

混凝土框架结构是建筑工程结构的另一主要组成部分, 混凝土施工期间, 混凝土原材料的质量需要进行严格的检 测与把控。保证混合原材料质量的基础下, 要对混凝土混合配比的比例合理性、准确性进行把控, 混凝土混合配比与 混凝土强度、刚度等性能之间直接关联。在实际混凝土施工期间还需要根据工程实际的要求, 对混凝土混合配比进行 科学调控, 并对混凝土混合搅拌施工、浇筑施工等进行严格的质量监控, 混凝土浇筑施工期间要对细节问题进行重点 关注, 在施工期间出现的细节性问题, 就会对混凝土结构质量产生不良的影响。因此混凝土浇筑衔接结构施工期间, 要保证衔接结构的坚固水平达到标准状态, 避免出现裂缝。

\section{2 建筑工程框架结构施工技术应用分析}

建筑工程框架结构施工包含很多环节, 每个阶段的工程施工都需要科学规范的应用施工技术, 来保证施工结构的 
质量和施工过程的安全。因而对施工技术应用规范性与高效性的保证非常必要, 下面就对建筑工程框架结构施工技术 的应用要点进行分析。

\section{1 钢筋施工技术}

在钢筋施工期间, 需要根据建筑工程框架结构设计要求, 对钢筋材料的规格、材质等内容进行确认, 保证施工钢 筋材料的适用性。钢筋模型要完全按照施工设计图纸进行施工搭建, 避免钢筋焊条连接的部位出现裂缝, 保证钢筋结 构施工的安全和承载力 ${ }^{[1]}$ 。钢筋材料的质量检验要由专门的施工人员负责, 在钢筋进场之前对钢筋材料的质检合格材料 进行验收检查, 并对钢筋材料进行质量抽检, 保证施工使用的钢筋材料符合施工设计与安全标准, 在施工的过程中如 果发现钢筋有破损或规格材质不符的情况，要及时进行处理，不能应用质量不达标的钢筋进行施工。

钢筋焊接施工期间, 施工技术人员可以对钢筋材料的性能进行检测, 保证钢筋结构的承重能力达到建筑工程施工 标准, 避免焊接期间钢筋材料断裂。并且在钢筋焊接之前要对钢筋结构焊接位置进行测量确认, 将定位测量的误差进 行严格控制, 保证钢筋放样、下料施工控制的精细性, 钢筋焊接位置若是出现偏差, 钢筋焊接结构受力会不均衡, 容 易出现变形等不良情况, 影响钢筋结构的质量。在钢筋放样施工的过程中, 对钢筋长度进行测量, 合理规划钢筋焊接 布局, 为焊接施工留有充足的空间。同时在焊接时, 要控制好焊接钢筋的温度, 避免钢筋材料收缩变形。钢筋施工完 成之后要做好质量检查工作，保证钢筋工程结构合格后再进行下一阶段的施工活动。

\section{2 模板施工技术}

建筑工程模板施工期间, 最重要的是模板连接结构的质量控制, 必须保证连接部位的受力水平能够满足框架结构 的要求。在实际开展建模施工之前利用技术手段进行模拟施工构建操作, 对模板的设计效果进行验证, 从而保证建模 顺序与技术方法应用的合理性。建模施工质量对于框架结构影响较大, 要安排专业的模板施工技术人员开展施工活动, 保证施工操作的规范性和技术的专业性。在建模施工时, 模板与施工地面水平线之间要保持 $90^{\circ}$ 的状态, 建模开始之 前先在建模的场地安装好支撑结构, 保证建模过程的稳定性, 对建模各个尺寸、位置进行精准的控制。

建模期间钢筋混凝土元件的位置, 要严格按照图纸标注位置进行确定, 利用先进的测量仪器进行定位, 对人为操 作误差进行避免。模板连接部位的强度要加强, 混凝土施工期间对模板施加的外部压力比较大, 要保证模板连接结构 能够承受得住, 不会出现裂缝等质量问题。为了加强模板的稳定性, 可以在模板之间使用对拉螺杆进行固定。模板施 工要按照正确的顺序推进开展, 梁、板模板的安装, 确定各个模板准确位置之后, 要先进行主梁模板的安装, 然后进 行次梁的安装, 安装完成之后要进行梁口、标高检查，在梁底模板两边拉线进行测量，保证安装精准性。

\section{3 混凝土施工技术}

混凝土施工是一项比较系统的施工环节, 首先对混凝土材料质量进行检查, 根据建设工程框架结构设计文件, 确 定混凝土材料质量标准, 按照标准选购符合建设质量标准的混凝土材料, 要在质量口碑良好的建材销售企业购买混凝 土材料, 并对应用的混凝土材料质量合格证书、质量检验证明等相关材料进行查阅。并要保证混凝土材料的性能与数 量都能满足建筑框架结构施工需求。其次, 混凝土混合配比比例的科学调控, 混凝土材料配比不同, 混合而成的混凝 土强度、硬度等性能会存在差异, 要根据框架结构建筑施工对混凝土质量的要求, 来对混凝土混合材料配比比例进行 计算和合理设计。

合理控制混凝土的粗细、硬集料、水泥、沙子和砾石、添加剂等应用的含量, 保证混合的混凝土质量达到建筑工 程要求标准 ${ }^{[2]}$ 。最后, 混凝土注射技术应用时, 在注入混凝土之前, 必须进行严格的注入混凝土计算, 明确模具的位置 和注入混凝土的深度。在浇筑混凝土的过程中, 必须逐层浇筑和振动, 以确保浇筑混凝土的均匀性、密度和硬度, 混 凝土浇筑施工要连续进行, 不能间隔过长的时间, 避免影响浇筑混凝土结构的质量。同时混凝土振捣的方法要合理选 择, 对混凝土浇筑的进程与时间进行科学规划和严格的控制, 针对混凝土浇筑位移与变形问题进行全面预防, 浇筑施 工与振捣施工之间要及时衔接, 振捣要遵循快插慢拔的原则, 不能出现漏振或超振的现象。

\section{4 剪力墙施工技术}

剪力墙是框架结构中的主要承重结构, 其中剪力墙内壁施工技术应用优势明显, 可以强化剪力墙结构的承载力, 还可以美化建筑结构。剪力墙结构的厚度规格主要有 $40 \mathrm{~cm} 、 31 \mathrm{~cm} 、 30 \mathrm{~cm} 、 20 \mathrm{~cm}$ 四种, 具体施工期间可以根据设计要求进 
行合理的选择, 剪力墙内部隔板的材料要进行优选, 综合考量材料的经济性和性能、美化效果等因素, 现在比较常用的 就是小型空心砌块。内墙铺设施工期间, 将空心砖应用于铺路框架的墙壁, 可以有效强化结构抗震性能和内壁稳定性 ${ }^{[3]}$ 。

\section{3 结束语}

框架结构在建筑工程当中应用, 能够提升工程建设空间利用率, 保证建筑工程结构质量与安全的同时能够节约成 本, 促进建筑工程项目经济效益的增加。因而科学规范的应用框架结构施工技术, 强化框架结构的施工质量, 规避施 工安全风险，对建筑工程企业的可持续发展有现实意义。

\section{[参考文献]}

[1]许明. 建筑工程高支模施工技术探讨-一以某钢筋混凝土框架结构厂房的施工为例 [J]. 四川水泥, 2021 (1) : 206-207.

[2]张会琛.建筑工程框架结构的建筑工程施工技术分析 [J]. 城市建筑, 2020,17 (32) : 146-148.

[3] 马翔.建筑工程框架结构的施工技术分析 [J].中国建筑金属结构,2020(11) : 116-117.

作者简介：李乃瑛（1964.4-)，目前职务：高级工程师。 